\title{
УПРАВЛЕНИЕ МНОГООБРАЗИЕМ В ЭПОХУ ТРАНСНАЦИОНАЛИЗМА: ПЕРСПЕКТИВЫ И ОГРАНИЧЕНИЯ В ОБРАЗОВАТЕЛЬНОМ ПРОСТРАНСТВЕ
}

\begin{abstract}
В статье на материалах проведенного исследования поднимаются вопросы, связанные с особенностями инклюзивного образования детейинофонов в России. Рассматривая текущую ситуацию в социальной политике в области инклюзивного образования, мы учитываем транснациональный характер современных миграционных процессов. Их специфика соотносится с вариативностью и трансформациями дискурса об «адекватности» адаптационных мер, долгое время содержательно раскрывавшихся в логике ассимиляции. Институт образования, в частности, школа, является одним из ключевых каналов инклюзии этнических и культурных групп. В связи с этим нами предпринимается попытка сделать видимыми основные особенности повседневного контекста образовательного процесса детей из семей с миграционным опытом. В статье рассматривается, с одной стороны, как этот процесс оценивается учителями и кураторами, работающими с детьми-инофонами, с другойкаким образом руководство лицея и педагоги осуществляют репрезентацию деятельности проекта в публичной сфере, в частности то, как отражается образовательный процесс «Перелетных детей» в социальной сети Facebook. В рамках теории репрезентации видимые или акцентуированные различия обычно воспринимаются в качестве производящих отношения власти. Формирование публичного образа субъекта в таком
\end{abstract}

Мария Андреевна Козлова - к. и.н., доцент, гл.н.с., Международная лаборатория исследований социальной интеграции, Национальный исследовательский университет «Высшая школа экономики», Москва, Россия. Электронная почта: makozlova@hse.ru

Игорь Станиславович Михеев- аспирант, факультет социальных наук; стажер-исследователь, Международная лаборатория исследований социальной интеграции, Национальный исследовательский университет «Высшая школа экономики», Москва, Россия. Электронная почта: mikheevigst@gmail.com 
случае оказывается определяющим фактором его дальнейшего восприятия в обществе. Поэтому анализ специфики представлений о той или иной группе детей важен с точки зрения понимания возможного отношения к ним как внутри коллектива школы, так и вне нее- со стороны родителей и других социальных агентов. Мы предполагаем, что в зависимости от особенности представления проекта на публичных площадках формируется общий образ лицея и его руководства. Нашей работой мы отвечаем на вопрос о том, каким образом интерпретация культурных различий педагогами может отразиться на подходе к образовательному процессу и характере социально-культурной инклюзии детей из семей с миграционным опытом.

Ключевые слова: транснационализм, образовательная политика, социальнокультурная инклюзия, эссенциализм, мультикультурализм

DOI: 10.17323/727-0634-2020-18-4-657-672

Преобладание в научном дискурсе о проблемах миграции концепта «адаптация» в индустриальную эпоху соответствовало идее «плавильного котла» и исходило из предпосылки «конечности» миграционного движения населения (Донских 2010; Михайленко 2014). Однако трансформация «лица» миграции сегодня требует осмысления некоторых его типических проявлений с новых позиций. С развитием современных транспортных и коммуникационных технологий миграция трансформировалась из межнациональной в транснациональную. Относительно недавний термин «транснациональная миграция» описывает разнонаправленное движение мигрантов, которые поддерживают тесные контакты в странах происхождения, т.е. в пространстве, перекрывающем государственные границы (или игнорирующем их). Иными словами, теряют определенность не только пространственные, но и временные границы (Lie 1995): транснационализм приводит к смене старых концепций однонаправленного движения мигрантов представлениями о неограниченном пребывании в разных странах. С этой точки зрения, мигранты больше не могут характеризоваться как люди, лишенные корней, «выкорчеванные» из родной почвы, окончательно разорвавшие связи с родиной. Напротив, их повседневная жизнь оказывается определяемой «множественными и постоянными взаимосвязями, преодолевающими государственные границы», а социальная идентичность - «ориентированной на более чем одно национальное государство» (Schiller et al. 1995: 50). Соответственно, установка на ассимиляцию (как со стороны мигрантов, так и со стороны принимающего общества) оказывается принципиально неэффективной в контексте новых вызовов и целей взаимодействующих сторон.

Способствуя росту этнокультурного многообразия и поддерживая отход от ассимиляционных моделей, транснационализм несет вызов политическим силам принимающих стран, поскольку переопределяет понятие 
интеграции мигрантов и задает новые ценностные ориентиры и цели: соглашаясь с необходимостью создания общего культурного пространства как условия, в том числе, и индивидуальной свободы (Taylor 1992; Tully 2008), принимающее общество обязано предоставить меньшинствам возможность заявить о своих потребностях- вступить в диалог с другими группами с тем, чтобы примирить различные практики. Ориентиром процесса интеграции меньшинств становится, таким образом, гарантия, что их проблемы и интересы будут услышаны, несмотря на невыгодное положение, обусловленное возможными отличиями от принятых в доминирующей культуре конвенций. Предпочтение такого рода интеграции становится вопросом защиты индивидуальной свободы и выравнивания групповых статусов.

В контексте транснационализма особенную актуальность приобретает изучение феномена трудовой семейной миграции. В исследовании, посвященном возможностям адаптации детей из семей мигрантов в школах Москвы и Подмосковья, одним из социальных и образовательных барьеров выделяется высокая мобильность этих семей (Деминцева и др. 2017: 82). Вынужденное неоднократное включение ребенка в новую школьную среду, расставание с некоторыми членами семьи способствуют нарастанию неуверенности в текущих жизненных условиях и провоцируют эмоциональный стресс, что сказывается как на общем уровне успеваемости, так и на качестве процесса социокультурной адаптации.

При разработке регулятивных мер, охватывающих сферу образования, исследователи, политики и представители педагогического сообщества вынуждены учитывать растущую сложность условий и мотиваций всех акторов, включенных в образовательное пространство (Douglass, Thomson 2010). Обучение детей-мигрантов языку «местного» населения выступает в роли ключевого аспекта помощи в адаптации, независимо от перспектив и конечных целей миграционного движения, поскольку знание языка позволяет контактировать за пределами своей этнической общины, уменьшает чувство беспомощности и зависимости. Таким образом, наряду с решением образовательных задач, школьное образование, и в особенности- обучение языку, ориентировано на включение детей мигрантов в новое для них социальное и культурное пространство, что, в свою очередь, способствует предотвращению маргинализации и созданию условий для участия в жизни страны.

Сфера образования и миграционная политика- две политические области, которые напрямую связаны с вопросами конструирования гражданской и этнокультурной идентичностей, консолидации представителей различных этнических групп в общегосударственном контексте, конструктивной интеграции населения. На декларативном уровне ключевым ценностным ориентиром комплекса процессов интернализации образовательной среды представляется равенство всех участников образовательного процесса: 
Образование, квалификация, специальности-не только самоценность, но и инструмент, способ достижения целей, капитал для инвестирования. В этом инструментальном (или, может быть, утилитарном) смысле получение возможностей в сфере образования означает доступ в дальнейшем к другим общественным благам (Константиновский 2010: 40-41).

Однако, как показывает опыт оценки школьной успеваемости по результатам масштабных мониторингов, таких как TIMSS/PIRLS и PISA, в большинстве стран, высоко привлекательных для мигрантов (ОЭСР, в т.ч. РФ), детииммигранты отстают в успеваемости от детей представителей большинства более чем на два года (Buchmann, Parrado 2006). Семьи мигрантов, как правило, обучают детей в школах с более низкими показателями академической успешности и конкурентоспособности учащихся, часто характеризующихся неблагоприятными явлениями и условиями в классах. Стоит отметить, что исследования (Деминцева, Пешкова 2014; Деминцева и др. 2017), проведенные в московском регионе, позволяют утверждать, что причиной подобной дифференциации зачастую служит недобор учащихся в школах со «сложным социальным контекстом». В такие школы проще поступить, что является крайне важным фактором, определяющим подобный выбор в условиях дефицита времени и ресурсов у большинства родителей-мигрантов. В подавляющем большинстве стран, включенных в исследование PISA, по меньшей мере четверть детей-иммигрантов второго поколения посещали школы, в которых иммигранты составляли более половины от общего числа учащихся. С другой стороны, в странах с высоким уровнем иммиграции, где хорошо налажены программы языковой поддержки в области дошкольного образования и начальной школы, четко определены цели, стандарты и системы оценки, показатели детей второго поколения из числа иммигрантов намного ближе к среднему уровню по стране, что свидетельствует о роли государственной социальной политики в этой сфере (EUMC 2004).

Эмпирически фиксируемая ситуация требует не только существенной коррекции методологических ориентиров, сложивших образовательную систему, но и ее «идеологической» перенастройки. Перед современными образовательными учреждениями стоят задачи приобщения всех вовлеченных в образовательный процесс акторов (родителей, педагогов, администрации, учащихся) к идее разнообразия, демонстрации гибкости и креативности в работе и решении проблем, устранения и предупреждения любого риска дискриминации, поощрения сотрудничества и диалога всех участников образовательного процесса (Council of Europe 2011). При этом оценка актуального уровня готовности участников образовательного процесса к подобной трансформации ценностных ориентаций и встраивания в меняющуюся инклюзивную образовательную среду представляет практическую проблему, что рождает ряд теоретико-методологических задач.

В представленной статье анализируется повседневность инклюзивного образования глазами учителей, непосредственно включенных в работу 
с детьми из семей иммигрантов. Методологическая актуальность этой работы обусловлена выбором объекта: учителя, работающие с детьми иммигрантов, в исследованиях, нацеленных на изучение адаптации мигрантов, т.е. избирающих в качестве объекта самих мигрантов или их детей, предстают в качестве экспертов, оценивающих паттерны поведения и стратегии адаптации мигрантов. Мы ставим под сомнение «экспертность» знаний учителей, работающих с мигрантами, и на основе анализа конкретного кейса выделяем ценностно-нормативные установки учителей в отношении учеников-инофонов.

\section{Кейс «Перелетные дети»}

Эмпирическое исследование реализовано нами в стратегии case-study, что предполагает всестороннее изучение случая посредством этнографического подхода (контекстуального включения в локальную культуру и практики сообщества/организации/института). Данные, использованные при написании статьи, получены такими методами сбора как полуструктурированное интервью с учителями и кураторами (как основной способ сбора информации) и визуальный анализ контента в социальной сети Facebook. С целью сохранения анонимности из-за сензитивности задаваемых вопросов имена информантов удалены, а их возраст изменен.

Изучаемый проект «Перелетные дети» реализуется на базе частного лицея «Ковчег XXI века». Он является благотворительным образовательным проектом, финансирование которого производится из средств лицея и частных пожертвований. Программа рассчитана на годичный период образования детей из семей мигрантов в русскоязычной среде. Занятия проводятся второй год, в рамках проекта дети делятся на две группымладшую (7-10 лет) и старшую (11-12-17 лет). Семьи, чьи дети участвуют в проекте, демонстрируя потребность в получении образования, испытывают сложности с организацией обучения детей в государственной школе, обусловленные низким уровнем владения русским языком как самими родителями, так и детьми более старшего возраста, отсутствием материальных ресурсов у семьи и/или её (неурегулированным) правовым статусом: «Он [директор лицея] сам ходил по стройкам и предлагал людям учиться, и потом уже, через какое-то время, мы набрали несколько человек и превратили в класс» (учитель, ж., 23 года).

Педагогический коллектив для «перелетных детей» подобран из учителей-предметников и кураторов учебных групп, в обязанности последних входит классное руководство группы, методическая поддержка проекта и осуществление связей с общественностью. Кураторы, нанятые для работы в рамках адаптационной инициативы, руководят социально-инклюзивным процессом. Учителя-предметники работали в лицее до начала реализации программы, специальной подготовки для работы с детьми- 
инофонами они не проходили: «Видим детей, значит, как говорится, должны работать с ними» (учитель, ж., 57 лет). Мотивация учителей отлична от мотивации кураторов, в какой-то мере для последних работа с «перелетными детьми» более обоснована, однако не выходит за рамки инструментального отношения к работе в школе:

Не буду лукавить - для меня тут нет никакого благородного поступка, просто мой жизненный принцип- нести просвещение в массы. Образование должно быть доступно для всех, я считаю. И также, может быть на подсознательном уровне помог тот факт, что я тоже отношусь к национальному меньшинству (куратор, ж., 24 года).

Таким образом, определение миссии и цели проекта неоднозначно трактуются педагогами: для кураторов «перелетные дети»-«рабочее поле» по социально-культурной инклюзии, для некоторых учителейспособ получения дополнительных часов нагрузки. Противоречиво и отношение к детям-инофонам: с одной стороны, информанты постоянно воспроизводят лексему «это такие же дети», однако при описании хода образовательного процесса или существующих проблем-акцентируется специфичность контингента учащихся:

Она не воспринимала ничего, потому что привыкла борщ готовить...

Было заметно даже на выпускном, когда мы все фотографировались, она села на пол и положила руки директору на коленки. Вот это вот восточное у них - села на колени возле мужчины. И мальчики- они не воспринимают тебя (учитель, ж., 25 лет).

Культуро- и этноцентризм, характерные для этих комментариев, свидетельствуют об эссенциалистской интерпретации культурных и социально-экономических различий (Grillo 2003), соответственно, предполагают определение «правильных» и «неправильных» ценностей, паттернов поведения и идентичностей, а также возможность «исправления» «неправильных» практик и усвоение «правильных» ценностей.

Само название проекта- «Перелетные дети»- накладывает отпечаток на интерпретации педагогами статусных характеристик учащихся. Дискурсивно слово «перелетные» вносит в фокус репрезентации детей-инофонов непостоянство их проживания на территории РФ, транснациональный характер миграции: «Сейчас они прилетели, отучатся и обратно вернутся? Вот, а, с другой стороны, оно как-то красиво звучит... Ну смислл действительно получается немного двоякий-что они прилетели-улетели» (учитель, ж., 23 года). Присутствует понимание вынужденного характера перемещения семей учащихся. В какой-то мере подобное наименование качественно предопределяет содержательную цель проектадать достаточные знания культуры и русского языка для последующего перехода детей-инофонов к обучению в государственной школе, но с учетом 
фактора их возможного возвращения в страну исхода: «Перелетные птиизь-перелетные дети, перелетные птицы улетают оттуда, где холодно, перезимовать, чтобы потом вернуться, когда станет хорошо на том месте» (учитель, ж., 25 лет). Таким образом, наименование проекта вносит описанный ранее аспект транснационализма в образовательное пространство, однако в интерпретациях педагогов этот аспект преломляется и видится не как перспектива, а как ограничение.

\section{Особенности интерпретации педагогами культурных различий}

Склонность к эссенциализации уже отмечена в оценках и интерпретациях культурных различий учителями и кураторами, как и сопряженное с ней оценивание других культур через критерии собственной. Так, в нарративах часто встречаются дихотомические конструкции «европейского» и «неевропейского» поведения, характеристики «цивилизованного» и «нецивилизованного» образа жизни, а также определения «дикости» некоторых аспектов традиционного уклада жизни этнических меньшинств: «Есть совсем ребята-дикие, которые только-только к нам приходят, вот, у них и с языком проблемы, и с пониманием куда они пришли и зачем-тоже большие проблемыл (учитель, ж., 23 года). Обобщения эссенциалистского характера возникают на уровне высказывания как педагогов, так и семей «рядовых» студентов (со слов некоторых учителей) в контекстах общего определения для той или иной этнической группы. Происходит это посредством приписывания той или иной этнической группе характеристик различного свойства- от «благодарности» до «наглости». Некоторые формы поведения детей также интерпретируются педагогами в качестве заданных принадлежностью к той или иной этнической группе (обратный процесс):

Заметила, что киргизские родители более мотивированы, более цивильны. Многие считают у нас, что киргизы более близки к цивилизации, чем таджики и узбеки, из тех, кто приезжает. У них поведенческие нормы более близки к европейским, а у таджиков и узбеков у них немножко другие (учитель, ж., 25 лет).

Социально-экономический статус семьи зачастую дополняет и расширяет спектр негативных аспектов, которые ложатся в основу эссенциализации, и подкрепляет ее изнутри: «Говорили: "Зачем mbl вот этого нищего сюда тащишь? Этого нам не нужно, здесь все здоровые, чистые дети"» (учитель, ж., 25 лет). Так, стереотип о «грязности» и «бедности» катализирует неприязнь не только у некоторой части студентов лицея и их семей, но и у отдельных представителей педагогического коллектива: «Некоторые родители жаловались, что они пришли в школу, чтобы 
учиться с детьми "их" уровня, что это все типа "отбросы, бедняки, они нецивилизованные, невоспитанные", и они не хотят, чтобы их дети с ними контактировали» (учитель, ж., 24 года). Однако, как отмечают сами педагоги, подобные стереотипы имеют свойство не соответствовать реальному положению бытовой ситуации ни в семье детей-инофонов, ни на уровне лицея в целом. Показателен в этой ситуации рассказ о волне педикулёза среди учебного года:

Когда у нас была вспышка вшей в том году, все думали на Перелетных. Вообще, вши-это нормально, вспышки каждый год были еще до Перелетных. Все думали на Перелетных детей, в итоге- мы обследовали всех «перелетных», ни у кого из них вшей не было. Это привезли пятиклассники (учитель, ж., 27 лет).

Обозначенные интерпретации воспроизводят логику дифференциалистского расизма (Балибар, Валлерстайн 2004), который- часто декларируя «благородные» цели (сохранения многообразия традиционных культур, государственной безопасности) - укрепляет межгрупповые границы и, соответственно, идейно исключает саму возможность инклюзии, провозглашаемую идеалом современного школьного образования.

\section{Процесс социально-культурной инклюзии в образовательном пространстве лицея}

Указанный диссонанс- между ценностью равенства доступа к образованию и стремлением не допустить «осквернения» доминирующей культуры инородными элементами- разрешается посредством трансформации идеи инклюзии. Она начинает репрезентироваться как ассимиляция. Так, интерпретация процесса адаптации к условиям и культуре принимающего большинства выражается учителями в терминах «перевоспитания», «привыкания», «агрессивной» интеграции: «Так как они живут в нашей стране, то мы их перевоспитаем, они должны приучаться $\kappa$ тому, как мы владеем этим» (учитель, ж., 53 года). Эссенциализированное восприятие культурных различий педагогами таким образом выступает в качестве фона культурных факторов, который характеризует адаптационную среду в качестве «плавильного котла»: «Mы уважаем ваши традиции, но у нас здесь для всех единые правила. Вы интернируетесь, вы адаптируетесь-будьте добры» (учитель, ж., 25 лет); «Даже в процессе обучения будь то русскому или лепке постоянно пропагандируются ценности демократии, ценности толерантности по отношению друг к другу» (куратор, ж., 24 года).

Исходя из оценок учителей, знание языка выступает основополагающим, а зачастую и единственным индикатором успешной реализации социально-культурной инклюзии. Данный паттерн может устанавливать 
свои ограничения на понимание педагогами процесса социально-культурной инклюзии в рамках этого проекта, переводя внимание с вопросов культуры и помощи по включению в принимающее общество на проблемы лингвистического образования.

Эффективность собственной работы педагоги оценивают в трех направлениях - успешное научение инструментальному знанию (русский язык, математика), приобретение способности открыто и доброжелательно взаимодействовать вне «диаспоры» (принимать и учитывать опыт и культуру других меньшинств, а не только большинства) и развитие культурных компетенций большинства. В последнее включаются светскость, демократичность, эгалитарность, толерантность, свобода и уважение. Процесс работы описывается так:

Если они видят на экране темнокожего актера и говорят: «ой, фу, это какой-то негр», бывало и такое тоже,- мы сразу начинаем беседу. Это провокация в какой-то степени,- а почему тебе не нравится? Он такой же человек, только другой и требует к себе такого же равного отношения (куратор, ж., 24 года).

Пресечение «традиционных» паттернов поведения у детей- одна из практик управления разнообразием, отличающаяся репрессивностью в сути и манере реализации. Подкрепляя ассимиляционную направленность инклюзивного процесса, учителя и кураторы используют директивные установки и запреты, предполагающие корректировку паттернов традиционного, патриархального поведения, которое является для них наиболее видимой репрезентацией различий. К примеру, так куратор отреагировала на приказной тон брата в отношении сестры, которая беспрекословно начала ухаживать за ним, подавая ему обед:

Так у нас здесь не работает, сегодня у нас [имя брата] наливает всем суп, и он с такой злостью, с такой ненавистью разливал этот суп. Ты не можешь так говорить, что тебе кто-то должен, а если говоришь, то вот- сегодня ты дежурный, все садятся (учитель, ж., 24 года).

Такие тактики используются и в отношении запрета разговаривать на родном языке: «Когда они болтают-делают это на своих языках, и у учителя есть рычаг-мы говорим только по-русски-сразу мертвая тишина. Это работает» (учитель, ж., 27 лет).

«Уроки дружбы»- совместные уроки для детей из разных классовкак одна из интегративных практик, реализуемых в рамках проекта, является примером формализованного процесса приобретения культурных компетенций через совместное обучение и общение. На уроках между учениками и «перелетными детьми» достигается эффект снятия эссенциализированного барьера, который позволяет детям в ходе безопасной коммуникации делиться особенностями своих культурных идентичностей. Ранее такие уроки проводились в лицее в качестве способа для сближения 
параллельных классов и детей разного возраста. Однако в применении к группам «перелетных детей» данная тактика приобрела инклюзивный эффект: «Ребята иуельм классом ходили к ним на историю, делились по группам, и там ... работали и с русскими девочками, и парни помогали. Отлично работали, и играли, и проблем никаких не возникало» (учитель, ж., 23 года).

Неформальные интегративные стратегии- еще один подход к оказанию влияния на установки и культурную идентичность детей. Они варьируются от практик совместного труда («рассадка», коллективные задания) до беседы на повседневные темы. Параллельно с институциализированными и формализованными практиками реализуются спонтанные неформальные практики приобщения детей-инофонов к паттернам массовой культуры:

Есть парень [имя], он тоже из проекта, он из 7-класса, уже с ними и тусит, они его и покрасили, раньше волосы черные были, представляете афганистанец, а сейчас ходит блондин крашенный. Потому что все парни покрасились в 7-м классе, и он тоже покрасился (учитель, ж., 23 года).

Открытое, свободное, не ангажированное общение со сверстниками позволяет детям-инофонам не только получить языковую практику от носителей, но и включиться в повседневный опыт, наполненный многообразными культурными образами, стать равноправными субъектами этой коммуникации. В какой-то степени это эффективная, но не массовая характеристика социально-инклюзивного процесса на уровне всего лицея.

По оценкам информантов, внутри жизненных миров педагогов и учащихся лицея произошли фундаментальные ценностные преобразования, которые позволили проникнуть в опыт других людей и шире посмотреть на сложность устройства различий и общества в целом. Некоторые учащиеся и учителя решили покинуть лицей, другие- изменили свое отношение, в том числе через опыт взаимодействия. Произошедшая трансформация установок оценивается оставшимися в лицее педагогами как позитивная:
Многие согласны с тем, что наш директор говорит о том, что дети должны знать все, что происходит за пределами «Рублевки»-о том, что есть какая-то жизнь за пределами вашего забора. Многие говорят спасибо за то, что посадили этих детей, они научили нас многому, мы узнали о том, что есть другие, другая жизнь, наши дети узнали, они стали интересоваться, общаться (куратор, ж., 25 лет).

Носит ли эта трансформация «системный» характер, что предполагает суть инклюзивного образования, или остается изменением индивидуального уровня и имеет неустойчивый- ситуативный- характер, демонстрирует анализ репрезентации проекта «Перелетные дети» в публичном пространстве Facebook, эксплицирующем предлагаемые педагогическим сообществом режимы видимости и интерпретации различий. 


\section{Репрезентация проекта в публичном пространстве: чьим голосом говорят «перелетные дети»}

Формирование режима видимости связано с практикой коммодификации визуального пространства. Поток насыщенной визуальной репрезентации теряет смысл, если мы не можем его считать или отличить от других репрезентаций. Определенность достигается посредством маркирования видимого нами образа, что предполагает принятие или переопределение предлагаемых значений, а значит - и властных отношений. «Я» имею власть так или иначе подписать фотографию в социальной сети, тем самым «я» наделяю данное изображение четкой коннотацией, определяющей смысл фотографии для всех остальных. Так производство подписи в социальной сети становится актом производства символической власти. Рассмотрим репрезентацию в социальной сети Facebook проекта «Перелетные дети» (рис.1) в сопоставлении с репрезентацией других классов лицея (рис.2).

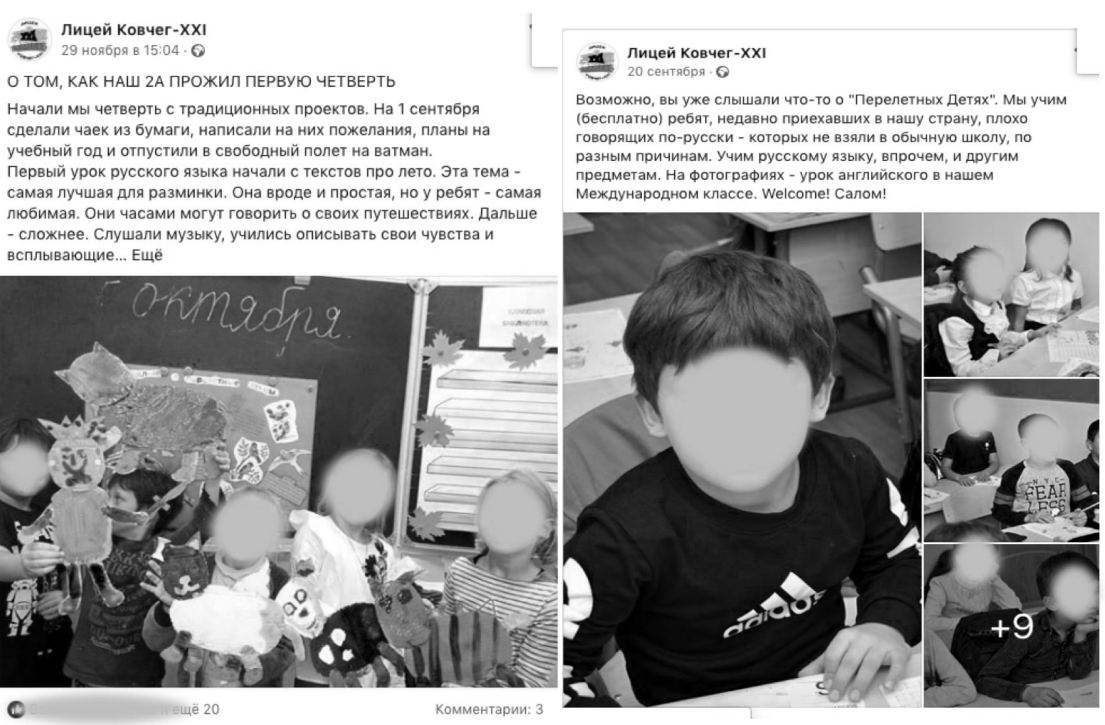

Puc. 1. Урок в группе «Перелетные дети» Puc. 2. Урок в обычном классе лицея

Как уже было отмечено, «пост» в социальной сети это не только визуальная, но и текстовая репрезентация. В рассматриваемом случае содержание «постов» демонстрирует в одном случае статусную дифференциацию «мы»-«они» («мы учим ребят, недавно приехавших в нашу страну»), в другом-интеграцию в единое «мы» («начали мы четверть..., сделали..., написали... и отпустили...», «слушали музыку, учились описывать свои чувства...»). Текст актуализирует и закрепляет визуальное фреймирование 
реальности. Образы «Перелетных детей» и учеников «2-А» не идентичны. В первом случае мы видим пассивность детей, на которых оказывается воздействие, во втором- дети активны, выражают себя через собственные поделки, стоят в своем классе. Можно предположить, что это только специфический подбор сделанных на занятии фотографий, но, если посмотреть на другие фотографии (рис. 3-4), будет видна аналогичная ситуация при равных условиях (уроке). «Перелетные дети» сидят ровными рядами и слушают педагога, ученики «5-В» и «3-Б» перехватывают инициативу, трансформируют пространство и социальную структуру класса и ведут занятия по «Египетскому счету».

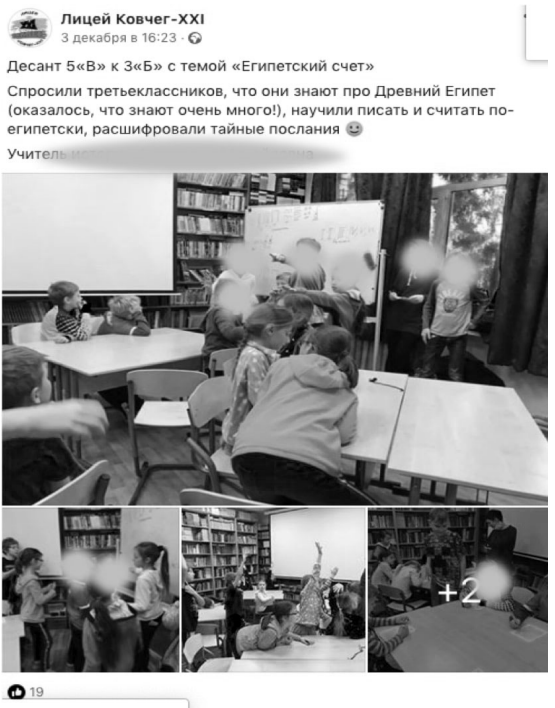

Рис. 3. Театрализованное занятие в группе «Перелетные дети»

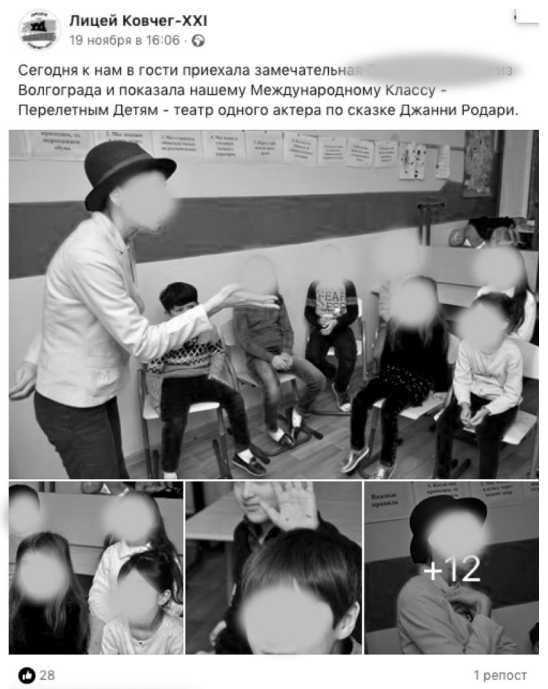

Puc. 4. Урок по теме «Египетский счет» (обычные классы лицея)

В первую очередь группа в Facebook нацелена на формирование образа у двух категорий лиц: родителей, уже отдавших своих детей на обучение в этот лицей, и тех, кто только собирается это сделать. Учитывая платный характер образовательных услуг в лицее, можно предположить, что излишнее присутствие в информационной среде заметок о детях из семей иммигрантов может вызвать неоднозначную реакцию некоторых родителей. Таким образом, фрагментарность и пассивность репрезентации класса, формируют своеобразное представление о существующем в группе лицея режиме видимости как о метафоричной замочной скважине, суть которой- осторожность в трансляции материала. Режим репрезентации построен на принципах тотального ограничения и контроля инаковости, что, в рассматриваемых случаях отражается в отчуждении «других» в текстах и визуальных образах, транслируемых в Facebook. Это становится 
основой объективации: изображаемые «перелетные дети» лишаются субъектности, позиции и голоса.

\section{Заключение}

В описанном кейсе интеграция детей-мигрантов реализуется на основе смешения противоположных установок- на ассимиляцию и адаптацию. Данные установки являются отражением способов интерпретации педагогами культурных различий. Одни привычные паттерны поведения вызывают негативную оценку учителей (к примеру, гендерные аспекты во взаимодействии детей) и попадают под «корректировку», а другие (к примеру, гастрономические запреты и предписания) оказываются в пространстве толерантного отношения. Таким образом интеграционную среду лицея можно определить как гетерогенную с точки зрения ценностно-нормативного наполнения, воспроизводящую разнонаправленные модели включения.

В характере механизмов управления разнообразием на уровне всего лицея можно наблюдать противоречивые тенденции: от гуманистической траектории - диалога, совместных, инклюзивных занятий, до репрессивных способов управления- порицания, наказания, манипуляции. Практики «перевоспитания», «корректировки», направленные на культурно-опосредованные типизации жизненных миров детей мигрантов, порождаются убежденностью некоторых педагогов в необходимости светской ассимиляционистской модели, в которой они видят залог эффективного преодоления противоречивых культурных коррелятов. Данный вывод подкрепляется посредством визуального анализа публикаций о «Перелетных детях» в социальной сети Facebook, который демонстрирует своеобразный «режим видения» способов проведения занятий. Фотографии, на которых запечатлены занятия «перелетных детей», отражают относительно формализованный ход уроков, об этом говорят расположение парт, репрезентируемые техники тел самих детей. В то же время на фотографиях уроков других учеников зачастую отражена реализация свободных норм, соответствующих идеалам «демократического лицея».

Полученные результаты позволяют выявить противоречивость ценностно-нормативных установок учителей в отношении паттернов поведения, которые оцениваются учителями в качестве «типичных» для детей-инофонов, что оказывается непреодолимым препятствием на пути реализации идеи групповой интеграции. Без осознанного отказа от стратегии ассимиляции меньшинств вряд ли возможно разрешение вопросов защиты индивидуальной свободы, выравнивания групповых статусов и выстраивание «агонального диалога» (Tully 2008), в ходе которого принимающее общество и сообщества мигрантов включаются в непосредственную дискуссию друг с другом. 


\section{Выражение признательности}

Статья подготовлена в рамках программы фундаментальных исследований Национального исследовательского университета «Высшая школа экономики» (НИУ ВШЭ) и с использованием средств субсидии в рамках государственной поддержки ведущих университетов Российской Федерации «5-100». Сбор эмпирического материала осуществлен с использованием средств гранта РФФИ 20-011-00870 «Социальная инклюзия в системе оснований интеграции российского общества: сравнительный анализ ценностей и практик в институциональных и неформальных контекстах».

\section{Список источников}

Балибар Э., Валлерстайн И. (2004) Раса, нация, класс. Двусмысленные идентичности. М.: Логос.

Деминцева Е. Б., Зеленова Д. А., Космидис Е. А., Опарин Д. А. (2017) Возможности адаптации детей мигрантов в школах Москвы и Подмосковья. Демографическое обозрение, 4 (4): 80-109.

Деминцева Е. Б., Пешкова В.М. (2014) Мигранты из Средней Азии в Москве. Доступно по ссылке: http://demoscope.ru/weekly/2014/0597/tema01.php (дата обращения: 29 апреля 2020).

Донских Т.П. (2010) Социально-психологическая адаптация студента-мигранта в новых социокультурных условиях. Вестник ОГУ, 12 (118): 67-172.

Константиновский Д. Л. (2010) Неравенство в сфере образования: Российская ситуация. Мониторинг общественного мнения: экономические и сочиальные перемены, 5 (99): 40-65.

Михайленко О.И. (2014) Формирование готовности к межкультурной коммуникации у студентов-мигрантов в поликультурной среде вуза. Известия КБГУ, 4 (2): 101-104.

Buchmann C., Parrado E. A. (2006) Educational Achievement of Immigrant-origin and Native Students: A Comparative Analysis Informed by Institutional Theory. In: D.P. Baker (ed.) The Impact of Comparative Education Research on Institutional Theory. Oxford: Elsevier: 345-377.

Council of Europe (2011) Intercultural Competencies in Social Services. Constructing an Inclusive Institutional Culture: Methodological Guide. Strasbourg: Council of Europe Publishing.

Douglass J. A., Thomson G. (2010) The Immigrant's University: A Study of Academic Performance and the Experiences of Recent Immigrant Groups at the University of California. Higher Education Policy, (23): 451-474.

EUMC (2004) Migrants, Minorities and Education. Доступно по ссылке: http://eumc.eu.int (дата обращения: 10 сентября 2019).

Grillo R.D. (2003) Cultural Essentialism and Cultural Anxiety. Anthropological theory, 3 (2): $157-173$

Lie J. (1995) From International Migration to Transnational Diaspora. Contemporary Sociology, 24 (4):303-306.

Pfeffer D. (2014) The Integration of Groups. Ethnicities, 14 (3): 351-370.

Schiller G. N., Basch L., Szanton Blanc C. (1995) From Immigrant to Transmigrant: Theorizing Transnational Migration. Anthropological Quarterly, 68 (1): 48-63.

Taylor C. (1992) Multiculturalism and the Politics of Recognition. Princeton: Princeton University Press.

Tully J. (2008) Public Philosophy in a New Key. Cambridge: Cambridge University Press. 
Maria Kozlova, Igor Mikheev

\section{MANAGING DIVERSITY IN THE ERA OF TRANSNATIONALISM: PERSPECTIVES AND LIMITATIONS IN THE EDUCATIONAL SPACE}

This article, based on a case-study, examines the inclusive education of foreign children in Russia. We take into account the transnational nature of modern migration processes. Their specificity lies in the variability of the discourse on the 'adequacy' of adaptation measures; for a long time, it has been largely revealed in terms of assimilation. Including the concept of transnationality in the field of analysis, it is becoming increasingly liquid and unstable in the global perspective. The social institute of education, in particular school, is one of the main channels for the inclusion of ethnic and cultural groups. In this regard, we consider special aspects of the everyday context of the educational process in the lyceum. In particular, we are interested in how this process is evaluated by teachers and curators working with these children. The article discusses, on the one hand, how this process is evaluated by teachers and curators working with these foreign children, and on the other, how the lyceum's leadership represent the project's activities in the public sphere, in particular, how the educational process of 'The Migratory Children' is represented on Facebook. Therefore, analysing the specific ideas about a particular group of children is important for understanding attitudes towards them both within the school team and from outside-parents and other social agents. We assume that depending on the particular presentation of the project on public venues, a general image of the lyceum and its leadership is being formed. In this work, we try to answer the question of how interpretation in various educational institutions is reflected in approaches to the educational process and socio-cultural inclusion as a whole.

Keywords: transnationalism, educational policy, socio-cultural inclusion, essentialism, multiculturalism

DOI: 10.17323/727-0634-2020-18-4-657-672

\section{References}

Balibar E., Wallerstein I. (2004) Rasa, naciya, klass. Dvusmyslennye identichnosti [Race, Nation, Class: Ambiguous Identities]. Moscow: Logos.

Maria Kozlova-Cand. Sci. (Ethn.), Ethnology and Anthropology, associate professor, International laboratory for Social Integration Research, National Research University 'Higher School of Economics', Moscow, Russian Federation. Email: makozlova@hse.ru

Igor Mikheev - PhD student, Faculty of Social Sciences, International laboratory for Social Integration Research, National Research University 'Higher School of Economics', Moscow, Russian Federation. Email: mikheevigst@gmail.com 
Buchmann C., Parrado E. A. (2006) Educational Achievement of Immigrant-origin and Native Students: A Comparative Analysis Informed by Institutional Theory. In: D. P. Baker (ed.) The Impact of Comparative Education Research on Institutional Theory. Oxford: Elsevier: 345-377.

Council of Europe (2011) Intercultural Competencies in Social Services. Constructing an Inclusive Institutional Culture: Methodological Guide. Strasbourg: Council of Europe Publishing.

Deminceva E. B., Peshkova V.M. (2014) Migranty iz Srednej Azii v Moskve [Migrants from Central Asia in Moscow]. Available at: http://demoscope.ru/weekly/2014/0597/tema01.php (accessed 29.04.2020).

Deminceva E. B., Zelenova D. A., Kosmidis E.A., Oparin D. A. (2017) Vozmozhnosti adaptacii detej migrantov v shkolah Moskvy i Podmoskov'ya [The Possibility of Adaptation of Migrant Children in Schools of Moscow and Moscow Region]. Demograficheskoe obozrenie [Demographic Review], 4 (4): 80-109.

Donskih T.P. (2010) Social'no-psihologicheskaya adaptaciya studenta-migranta v novyh sociokul'turnyh usloviyah [Socio-psychological Adaptation of a Migrant Student in New Sociocultural Conditions]. Vestnik OGU [Bulletin of OSU], 12 (118): 67-172.

Douglass J. A., Thomson G. (2010) The Immigrant's University: A Study of Academic Performance and the Experiences of Recent Immigrant Groups at the University of California. Higher Education Policy, (23): 451-474.

EUMC (2004) Migrants, Minorities and Education. Available at: http://eumc.eu.int (accessed 10.09.2019).

Grillo R.D. (2003) Cultural Essentialism and Cultural Anxiety. Anthropological theory, 3 (2): $157-173$.

Konstantinovskij D. L. (2010) Neravenstvo v sfere obrazovaniya: Rossijskaya situaciya [Inequality in Education: The Russian Situation]. Monitoring obshestvenogo mneniya [Public Opinion Monitoring: Economic and Social Change], 5 (99): 40-65.

Lie J. (1995) From International Migration to Transnational Diaspora. Contemporary Sociology, 24 (4): 303-306.

Mihajlenko O.I. (2014) Formirovanie gotovnosti k mezhkul'turnoj kommunikacii u studentov-migrantov v polikul'turnoj srede vuza [Formation of Readiness for Intercultural Communication among Migrant Students in the Multicultural Environment of the University]. Izvestiya $K B G U$ [Bulletin of KBGU], 4 (2): 101-104.

Pfeffer D. (2014) The Integration of Groups. Ethnicities, 14 (3): 351-370.

Schiller G. N., Basch L., Szanton Blanc C. (1995) From Immigrant to Transmigrant: Theorizing Transnational Migration. Anthropological Quarterly, 68 (1):48-63.

Taylor C. (1992) Multiculturalism and the Politics of Recognition. Princeton: Princeton University Press.

Tully J. (2008) Public Philosophy in a New Key. Cambridge: Cambridge University Press. 